\title{
An Illustration of Geographical Warfare: Bombing the Dikes on the Red River, North Vietnam
}

\author{
Yves Lacoste
}

1973. Antipode 5, 1-13. ${ }^{1}$

\section{[...] Preamble}

[...] Geography, as one mode of representing the world, is inevitably involved with ideological issues. Mass media continue to project geographical clichés and images; one notes, for example, how landscapes figure largely in films and advertisements. The kind of geographical knowledge taught in schools and repeated by students does not, at first glance, appear to have much practical import. Geographical discourse, influenced by the master-student pedagogical model of the late $19^{\text {th }}$ century, is not the only possible form for geographical reflection. Long before it was addressed to students, geography was addressed to kings, princes, diplomats, and military leaders. As a concise method of describing space, in both its human and physical characteristics (as we conventionally classify them), geography became transposed into terms amenable to management by the State, in the form of social organization and control, and also of warfare.

It is important that we gain (or regain) an awareness of the fact that the map, perhaps the central referent of geography, is, and has been, fundamentally an instrument of power. A map is an abstraction from concrete reality which was designed and motivated by practical (political and military) concerns; it is a way of representing space which facilitates its domination and control. To map, then, means to formally define space along the lines set within a particular epistemological

\footnotetext{
${ }^{1}$ Reprinted with permission from Richard Peet.
} 
experience; it actually transposes a little-known piece of concrete reality into an abstraction which serves the practical interests of the State machine; it is a tedious and costly operation done for, and by, the State. Large-scale maps (called in France the "cartes d'Etats Major") are made by and for state officials; no wonder, then, that in many countries such maps are filed with other military secrets.

But cartography is not the only link between geography and the power structure. Since the time of Herodotus - who, after all, was not writing "history", but doing a survey to promote the imperial interests of Athens - geographers have often, consciously or unconsciously, been information agents. Down through the centuries, they have paid particular attention to phenomena which would be of use to military and governmental leaders. Topography, for example, was described in terms of strategic and tactical interest; the distribution of population was described in terms of the administrative and political organization of space. The central notion of region, so perennially used in the discipline, derives from the Latin word regere (to rule). Etymologically speaking, then, a region is by definition a military region.

Many university geographers today, who regard their discipline as a science detached scholarship dedicated to knowledge for the sake of knowledge - would no doubt be shocked to learn the military and political nature of geographic thought. Since the beginning of the 20th century [...], when geography was taught in schools, there was an effort to conceal its political and military functions. Teachers have mystified geography: they spoke of "natural" and "historical" explanations of phenomena which were really the result of political strategy of the State and the economic strategy of large firms. This kind of mystification, which makes geography an ideological discourse separated from practical life, has made a profound impact on public opinion, and also on the teachers themselves. It becomes exaggerated (though less manifestly) by the mass of geographical images and clichés propagated in the cinema, press, and television.

One could certainly claim that geography's political and military function belongs to the past, to the discipline's pre-scientific phase. Many geographers today honestly consider their "science" as detached knowledge - while at the same time complaining that their opinions are not considered in spatial planning: In fact, although geographical discourse is overtly unconcerned with problems of power, today more than ever it is clearly linked with practical (political and military) interests. One does not have to look to the far-distant past for examples of strategies whose design and implementation demanded the intervention of geographers. The Indo-Chinese war provides the best and most carefully-articulated example possible.

"Ecological warfare", as the expression goes, could best be understood in geographical perspective. To achieve a limited number of political and military objectives there has been destruction of vegetation, the transformation of the physical characteristics of the soil, the deliberate precipitation of new erosional processes, the rupture of hydrological sys terns in order to change the level of the water table (so as to dry up wells and rice paddies), and also a radical change in the distribution of 
population. Such forms of destruction are not simply the unintended consequences of the massive scale of lethal means available for technological and industrial warfare; they are the result of a deliberate and minutely-articulated strategy, the elements of which are scientifically coordinated in time and space.

The Indo-Chinese war marks a new phase in the history of warfare, and also in the history of geography. For the first time in history, the modification and destruction of the geographical milieu (in both its physical and human aspects) is being used to obliterate those very geographical conditions which are indispensable for the lives of several million people. So today, more than ever, one has to become aware of the political and military function which geography has always had since its inception. In our time this function has assumed greater magnitude, and takes on new forms because of increased information, more technically-sophisticated means of destruction, and also because of progress in scientific knowledge. The title of an article in Newsweek (August 7, 1972): "When the landscape is the serious Enemy" is indeed significant.

\section{Responsibility of the Geographer and Public Opinion}

Geographical warfare has been waged in the most consistent fashion (for more than 10 years) in South Vietnam. Its results are cumulative and complex. Though more information is being made available (for example, in articles by Westing and Pfeffer) about different types of disaster (e.g., the effects of defoliation and craterization), we still do not know how these disasters combine and mutually reinforce their destructive effects in space, and together aggravate the long-term consequences for the quality of life for whole populations. Only a good cartographic survey could enable us to get an estimate of the impact of this geographical warfare. We could also seek the participation of the people (who are very good geographers) to gain perspective on this historically novel destructive enterprise.

It is now possible to show the role of geographical reasoning in the massive, unrelenting operation which was involved in the bombing of dikes in the Red River delta in North Vietnam. One cannot, of course, prove that professional geographers (and geography teachers) participated actively in the systematic choice of bombing sites; however, those who did design the strategy and tactics of bombing, demonstrated a powerful mastery of geographical information and geographical thinking. A careful and precise geographical analysis, at different levels, i.e., a map showing all the bombing sites, would demonstrate (in a manner irrefutable even by Pentagon spokesmen) that the attack on the dikes followed a perfectly deliberate and systematic plan. In fact, as the map would show, the dikes were not hit at points adjacent to major communication lines, industrial developments, or large cities; they were hit at points where their rupture, given the variegated conditions of the delta, would prove a catalyst for even greater disaster and more deaths. It is significant that most of the sites bombed during the months of May, June, July, August and September of 1972 correspond exactly with the points which were hit earlier during the Presidency of Johnson. 
I assert, on the basis of my professional geographic research on the Red River dikes during the summer of 1972, that these bombings were designed to precipitate a frightening catastrophe. If this catastrophe has fortunately not happened, it is not because it was not intended, but rather because the Vietnamese people made a gigantic attempt to repair the breaches (with earth accumulated after the 1964-1967 bombings), and especially because, during the summer of 1972, the floods on the river were particularly low - this is a phenomenon which occurs every 8-10 years. There is now statistical evidence from meteorological records that Southeast Asia as a whole, and particularly the highlands from which the Red River flows, experienced a comparatively low precipitation rate in the summer of 1972. In the middle of August, the time when floods are usually heaviest, the water barely reached the level of the dikes throughout the delta. I submit these arguments to criticism based on evidence which may have escaped my attention. I have repeatedly requested the publication of such aerial photographs as would prove my map inaccurate. Nothing, however, has been published.

Since geographers participate in the execution of this new kind of warfare geographical warfare - they should surely begin to analyze it, prove or denounce it, since this is one of the most serious kinds of destruction. Its effects are difficult, if at all possible, to repair. Geographical warfare can be waged anywhere in the world, and it is not yet over in Indo-China.

It is important to note the malaise in public opinion which followed press releases on the bombing of North Vietnamese dikes. This was probably a confused way of expressing people's consciousness that this is a new and irremediable form of warfare. This should illustrate well the ideological problems which, despite appearances, are bound up with geographical representation. Indeed, among the more deadly aspects of the Indochinese war today, the bombing of the Red River dikes in North Vietnam is especially serious and significant. International public opinion almost instinctively grasped this fact. People reacted in a way that made the problem of the dikes an extremely embarrassing one for the Pentagon and the [U.S.] Government.

And yet, throughout the war in Vietnam, the U.S. military establishment made no attempt to conceal the particularly deadly nature of certain forms of tactical or strategic action that became daily routine, ranging from the systematic use of napalm and various types of "anti-personnel" weapons, to carpet bombing by 852 planes. Indeed, a large proportion of people who, witnessed, through the mass media, the greatest deluge of fire and steel ever known to history, frequently had the reactions of a slightly bored theater audience as it watched the deployment of the subtlest and most terrifying methods of destruction.

This relative habituation was suddenly interrupted by information that there was the possibility, not to say certainty, of air attacks aimed at the North Vietnamese dike system. Many well-known persons felt it their duty to publicly express apprehension on a subject, which soon assumed such importance that the President of the United States himself felt obliged to challenge the testimony of people who had 
been able to see for themselves, that the bombings had indeed taken place. For the eminent men and women who had expressed feelings of growing concern were simply lacking in perception and were an easy prey to communist propaganda.

But shortly afterwards, in the face of increasingly numerous eye-witness reports, the White House on July 30 issued a statement in which it was acknowledged that a few dikes, because of their proximity to military objectives, might have been hit; at the same time they insisted that the damage could only be slight. It was pointed out in reply that this information was quite vague and that such documents as aerial photographs which could have proved the truth of the official assertions - at least in some cases - were lacking.

Hence the matter of the "bombing the dikes", so far from becoming a dead issue, assumed ever-greater importance: public opinion became alerted before the exact facts of the case were known. It was as though people were intuitively aware that destruction of these dikes symbolized a new form of warfare, as though they considered, for very profound reasons, that the fiercest of conflicts between men should remain quite distinct from the centuries-old struggle between the human species and the most formidable forces of nature.

Public anxiety and the embarrassment of the authorities would no doubt be just as great if, as a means of strategic action, it were a matter of unleashing typhoons, earthquakes or volcanic eruptions against civil populations. In fact it would appear that, when faced with the forces of nature, solidarity between [people], whatever their differences, is among the fundamental, implicit values upon which all cultures are based. Consciously or unconsciously, for thousands of years, [humans] have seen the hand of God or fate in natural catastrophes; still today the willful unleasing of natural forces appears to be the sacrilegious act of a sorcerer's apprentice.

But it is important to go beyond the symbols and the profound, subjective motivations the problem presents, in order to clearly examine the facts. These are essentially of a geographical nature; that is to say, they correspond to the interaction of "physical and natural data" and the "human factors". Even before the global crisis of our time became dramatically focused on this small part of the earth's surface, the Red River delta had for centuries, been an area in which the geographical interactions between "natural factors" and "human factors" were especially complex, and presented a sort of dramatic tension. In fact, there are few regions in the world where, in such a limited area, there exist so many human beings who have evolved such an efficient, subtle culture (compared with most non-industrial cultures) under such difficult conditions: that is with their stability constantly threatened by the forces of nature. 


\section{Why the Dikes?}

The Red River Delta (which under the French colonial regime, was called the Tonkin plain) forms an almost equilateral triangle of 90 miles to a side in which live some ten million people; in a number of places the population density is over 800 inhabitants to a little over a half square mile.

This plain is dominated by large mountains which, in summer, receive the very heavy rains of the monsoon. Because of this, the rivers flowing onto the plain are frequently subject to sudden and very heavy flooding. In high water, the Red River becomes an enormous stream, with a flow greater than 110,000 cubic feet per second $\left[3,080 \mathrm{~m}^{3} / \mathrm{s}\right]-$ a volume comparable to that of the Mississippi (120,000 cubic feet per second $\left[3,360 \mathrm{~m}^{3} / \mathrm{s}\right]$. The risings of the Red River and its affluents are not progressive and regular, but take place suddenly and quite irregularly in the middle of the summer. They are due, in fact, to the enormous quantities of rain that falls during heavy storms on the relatively close mountains; the water runs rapidly down the steep slopes and suddenly flows onto the plain.

Such rivers running down from deeply-eroded mountains transport vast quantities of alluvium - this explains the characteristic color of the Red River, which is filled with various kinds of reddish silt are also most of its affluent streams. The mass of material detached from the mountains is so great that these alluviums tend to be deposited on the bottom of the rivers and, little by little, the river-bed is progressively raised. Quite naturally therefore, the rivers flow above the general level of the plain, on a sort of alluvial cushion (or natural levee). This situation also exists in the Mississippi valley, with the difference that the Red River transports a relatively greater amount of alluvium and flows above a natural levee that is appreciably more pronounced than that of the Mississippi (20 to 25 feet [6.1 to $7.6 \mathrm{~m}$ ] higher than the level of the plain).

When the rivers rise, congestion by alluviums of the river-bed and the progressive elevation of the levees tend to make the river flow into the lower parts of the bed and sometimes important changes in course result. The principal stream divides into several branches which also flow on cushions above the plain and have a tendency to overflow into it at high-water time.

The implantation of human beings into the Red River delta, a marshy, malarial region periodically under water, was therefore particularly difficult. Even though this area combined natural features that were particularly negative (as regards human beings), it also held great potentialities. In the tropical zone the soil is usually subjected to bio-climatic processes that reduce its fertility and make it extremely fragile (lateritization [...]). However, the alluvial areas do not present this very serious inconvenience: constant deposits of silts and material resulting from erosion of mountains which, because of their height, are not subject to tropical conditions, compensates for the process of impoverishment of the soil. Thus the broad valleys and delta plains offer exceptionally favorable pedological conditions in the tropics. It is possible to expect a number of consecutive harvests with good results, the silt 
deposited during high water serving to restore fertility of the soil. On the other hand, outside the alluvium-treated zones it is not possible to cultivate the soil for more than two or three years consecutively, because of its poor agronomical potentialities and the violence of the processes of deterioration that set in as soon as the forest covering has been cut away.

The historical task of the Vietnamese people (like other peoples in tropical Asia) has therefore been to progressively confront the negative features of the geographical milieu. Little by little they have achieved mastery over the high water in order to profit by the positive features - i.e. the relative richness of the soil.

The dikes are thus a primordial geographical condition of existence for the people. The vast undertaking represented by construction of some 2,500 miles [4,023 $\mathrm{km}$ ] of dikes started principally during the Middle Ages. In order to accomplish a task such as this under extremely difficult conditions (every year the flooding threatened to wipe out the work that had been done during the dry season) the Vietnamese not only had to be able to deploy a large number of workers, but also needed an efficient organization that made it possible to group the workers in certain places and to see that they were cared for. Also needed was a profound understanding of the science of hydraulics; for the works were constructed with limited means, in such a way that they would resist the thrusts of the river. Once the dike was built, it had to be supervised and regularly kept up to combat cracks and to check the effects of erosion caused by rain, the river, or burrowing animals.

The realization of this network of dikes not only is evidence of extraordinary organization in each village community, but also on the part of the government, which was the only agency capable of concentrating great numbers of workers at strategic points in the area.

Today this area is organized on different levels: the big dikes following the course of the important rivers have a function that includes the entire delta, since a break at one point could bring about flooding of wide regions. In the event there is a break in one of the principal dikes, dikes running perpendicularly to the rivers have been built across lower-lying regions. Coastal dikes have been built to prevent flooding by sea-water, particularly when it is propelled by the extraordinary violence of typhoon winds.

But inside each division bordered by these major dikes, secondary dikes have been built to channelize the rain water towards points at which evacuation is possible. If the rain water falling on the surface of the rice-fields were allowed to accumulate, the rice-plants would rapidly die under water that is too deep. Control of hydraulic conditions, an essential feature of intensive rice culture, means controlling the waterlevel not only at the different points of the area under cultivation, but also from the standpoint of time (as dictated by the different stages of agricultural work and the growth of the rice plant). This water-control is accomplished in the cultivated area of each village by means of a network of small dikes and canals located inside the larger 
meshes organized by the secondary dikes which are laid out in accordance with the main lines of the major dikes.

Historically, the conquest of the delta must have begun with limited man-power in the upper parts of the delta, near where the rivers leave the mountains to emerge onto the plain. Gradually, as new rice fields could be laid out, due to the construction of new dikes, new manpower appeared, making possible increased construction, then increased agricultural progress, and so on.

The Red River delta is not the only alluvial plain in North Vietnam. The other plains, those of Thanh Hoa and Vinh for instance, followed a similar evolution. But these plains are much more extensive and the rivers that cross them are much smaller than the Red River. Hence the problems presented are less difficult to solve, and although they have been subjected to particularly intensive bombing, it is the Red River delta on which attention is concentrated at present. For undoubtedly the risks of catastrophic flooding are the most serious in the plain of the Red River (because of the river's powerful current at high-water time) and the number of human beings [threatened there] is the greatest.

\section{Where Have the Dikes Been Bombed?}

In the controversy between the people who denounced the bombing of the dikes in North Vietnam and an American administration which denied that these attacks were deliberate, it is possible to furnish documentation that may serve as lasting and easily-verifiable proof. Since the dike network forms an ensemble of a geographical nature it is logical to undertake a geographical analysis of the points at which the network has been hit by bombs. I made this investigation during a visit to North Vietnam with the International Commission of Inquiry into War Crimes, which took place from July 29 until August 13, 1972. During this period I was able to visit the principal zones in which bombing of dikes took place, and to verify, at various points, the correctness of a map of the damage done to the hydraulic installations (figure 1). This map was very precisely made, at my request, by technicians from the Ministry of Hydraulics of the Democratic Republic of Vietnam. It can be easily verified from the frequent photographs taken by the U.S. Air Force. 


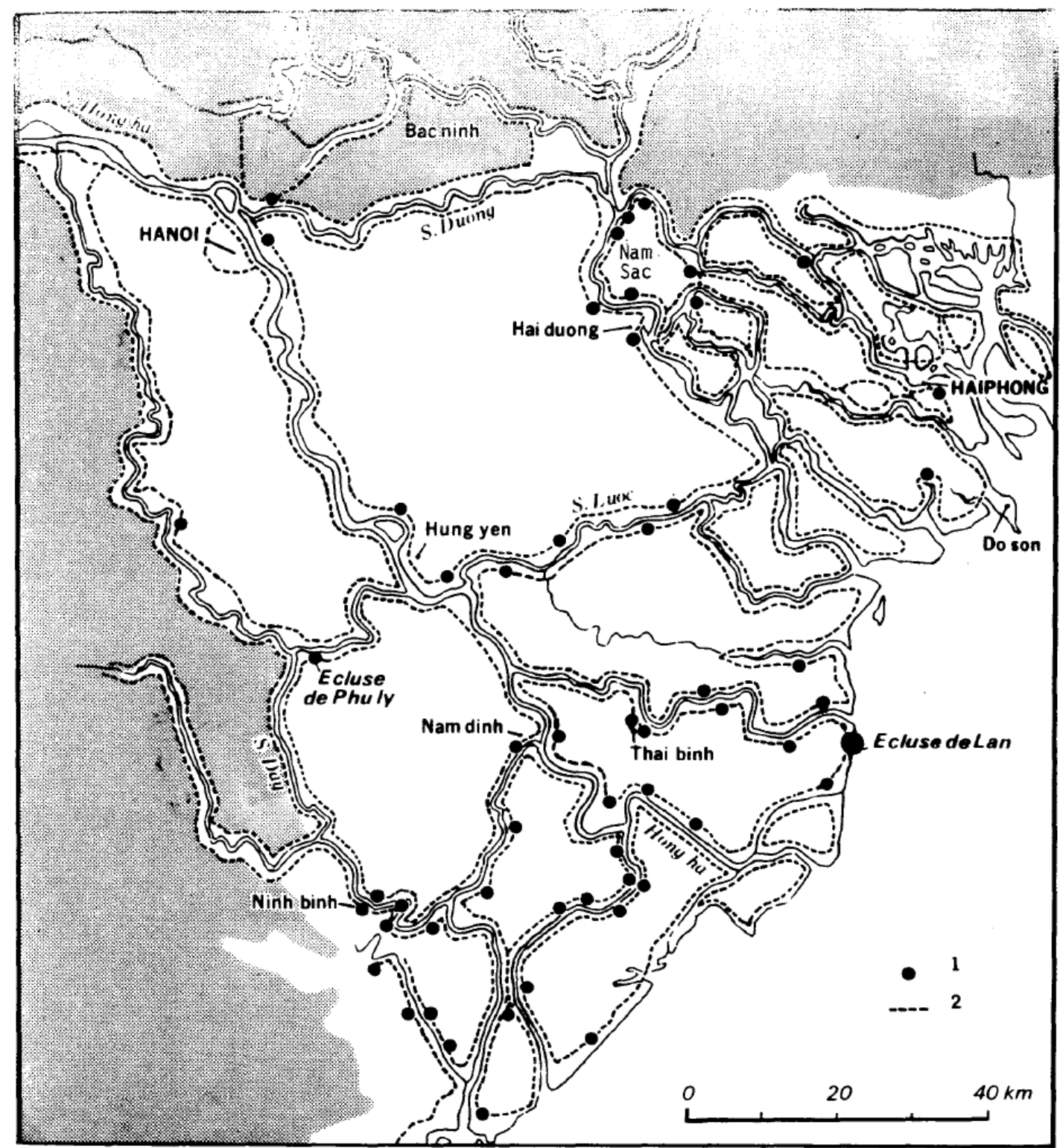

Figure 1: Bombing points May-August 1972; 1 = bombing points on dikes, $2=$ line of principal dikes

During the period April 16 to July 31, 1972 (bombing of the dikes continued later) the hydraulic installations in North Vietnam were the objective of over 150 attacks from the air, and they were hit in 96 different places. The International Commission of Inquiry into War Crimes decided that it would be preferable to concentrate its investigation on the Red River delta. The bombings that took place in the southern provinces of North Vietnam were so concentrated, on such a restricted 
area, that it is difficult to distinguish the ones that aimed at a hydraulic installation from those that had another type of objective.

\section{The Bombing of the Dikes in the Eastern Part of the Delta.}

Out of the 96 places at which the dikes were hit by bombs, 58 are situated in the Red River delta. If we examine the map of these places attentively, we immediately notice the following situation: almost all of these places - 54 out of 58 - are located in the eastern part of the delta, from the district of Nam Sachs in the north, the province of Thai Binh in the center, to the regions of Nam Ha, Nam Dinh and Ninh Binh in the south. Four bombing points on hydraulic installations lie outside this area: that is, two near Hanoi and two by the Phuly Locks in the Day River.

The American administration in fact acknowledges this pinpointing (which on the contrary had not been mentioned thus-far by the Vietnamese authorities) and claimed that it furnished a favorable argument for their line: the American administration declared in fact that if the bombing of the dikes were intended to bring on serious floods, they would have aimed at the western part of the delta, that is to say upstream just the part that was, for the time being, spared.

A more careful examination of the geographical conditions permits us to draw opposite conclusions. In point of fact, the Red River delta can be divided schematically into two quite different parts: the western part in the upper delta, where the rivers emerging from mountainous valleys contain lots of alluviums and where, before they were diked, the rivers had progressively built up a large number of alluvial cushions, as the course of the river changed; and the eastern, lower delta, where the rivers carry a lesser quantity of alluvium (since it has been deposited upstream) and flow above natural levees that are less high (figure 2). These rivers diverge toward the sea, like the spokes of a wheel. Because of this fact, there are wide, easily-flooded flats between the alluvial cushions. These differences of configuration between the upper and the lower delta have important consequences for the topographical localization of the villages: in the upper western part the villages have been built above these easily flooded areas on top of the alluvial cushions which, as we have seen, are particularly numerous and involved. In the eastern part of the lower delta most of the villages are located below the level of the rivers, in areas easily-flooded should a break in the dikes occur. 


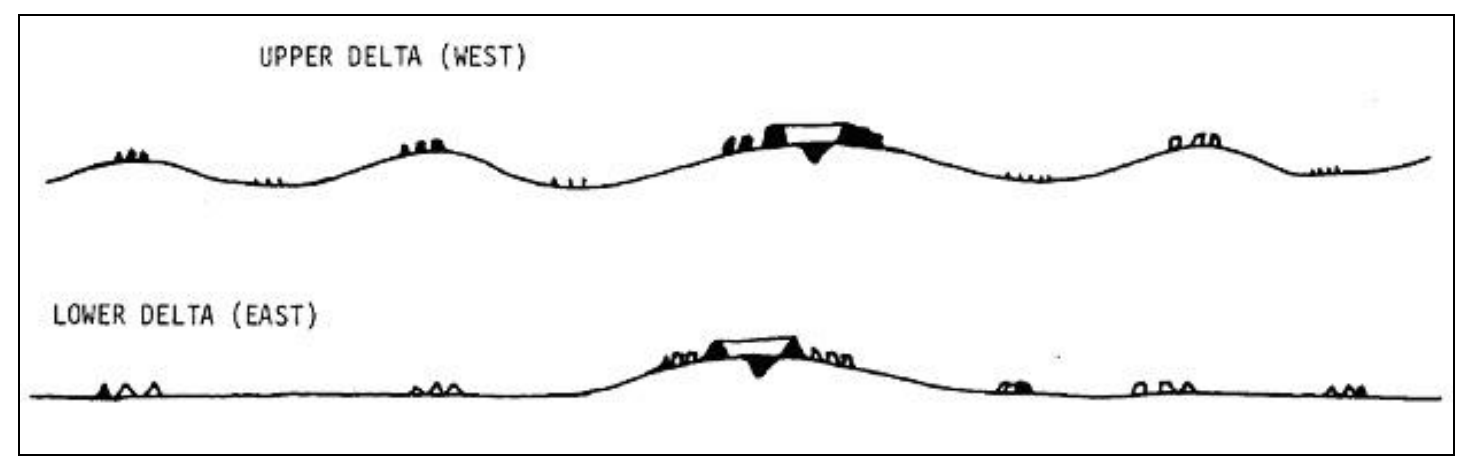

Figure 2

It just happens that a large majority of the bombed dikes are situated in the eastern part of the delta, where most of these easily-flooded villages are to be found. It may be argued that these were aimed at military targets located near, or on, the dikes. If this were so, they could not have avoided more frequent hits on the dikes situated in the upper delta, near Hanoi, for instance, where military objectives were often attacked, without harm to the dikes. The dikes in the lowermost region, which is situated between Nam-Sach and Haiphong, have thus far hardly been bombed at all. Actually, in this part of the delta, the rivers cease to flow above natural levees, having deposited most of their alluviums upstream. This no doubt explains why the dikes in this zone have not been bombed; the effect of destroying them would be less disastrous than in other places.

Thus, it is possible to conclude that the bombing of the dikes was concentrated in the eastern part of the delta, which is also the most densely populated and the most important from the standpoint of agricultural production. This is proof of the deliberate and systematic nature of these attacks, since they were localized exactly in the area in which their effects could be most serious and where most of the easily flooded areas are to be found.

\section{A More Detailed Analysis of Bombing Points}

Another level of geographical analysis consists in observing, in a very precise manner, the bombing points within this eastern part of the delta. For the most part, these points of destruction are not the result of random hits, but points at which absolute soundness is of special importance to the organization of the hydraulic system. In fact, the most frequently hit points on the dikes are the ones that, at highwater, are subjected to unusually strong pressure by water. The dikes have been attacked in the concave part of the bends or, as in the northern part of the Nam-Sach district, at points where they are subjected to the perpendicular pressure of an especially powerful current resulting from the confluence of six rivers (figure 3 ). It is 
literally impossible for there to have been "military targets" at all of these points, which are precisely those essential to the water-defense system. It should be emphasized that except in the Hanoi and Haiphong areas (where it is true that there are highways using the roadbed formed by the dikes) the greater part of the dike network would not be capable of standing up to automobile traffic. In the ten or so places that we visited to determine the effects of bombing on the dikes we were able to note that they had not been surfaced with a round-base material that would make automobile traffic possible. Similarly, at none of these points of observation were we able to detect the presence of an objective other than the one constituted by the dike (at an especially essential point). The fact that the dikes were hit at particularly sensitive points far from any other target is another argument in support of the hypothesis that there existed a deliberate, systematic strategy of destruction of the network of defense against high water. Relatively frequent use of time-bombs against hydraulic installations gives even greater credence to this hypothesis, since it is impossible to see what use time-bombs would offer against convoys or mobile military installations.

One of the most striking examples of proof that a methodical strategy was carried out against the dike network is furnished by an examination of the attacks against different types of hydraulic installations in the southern part of the Thai Binh province.

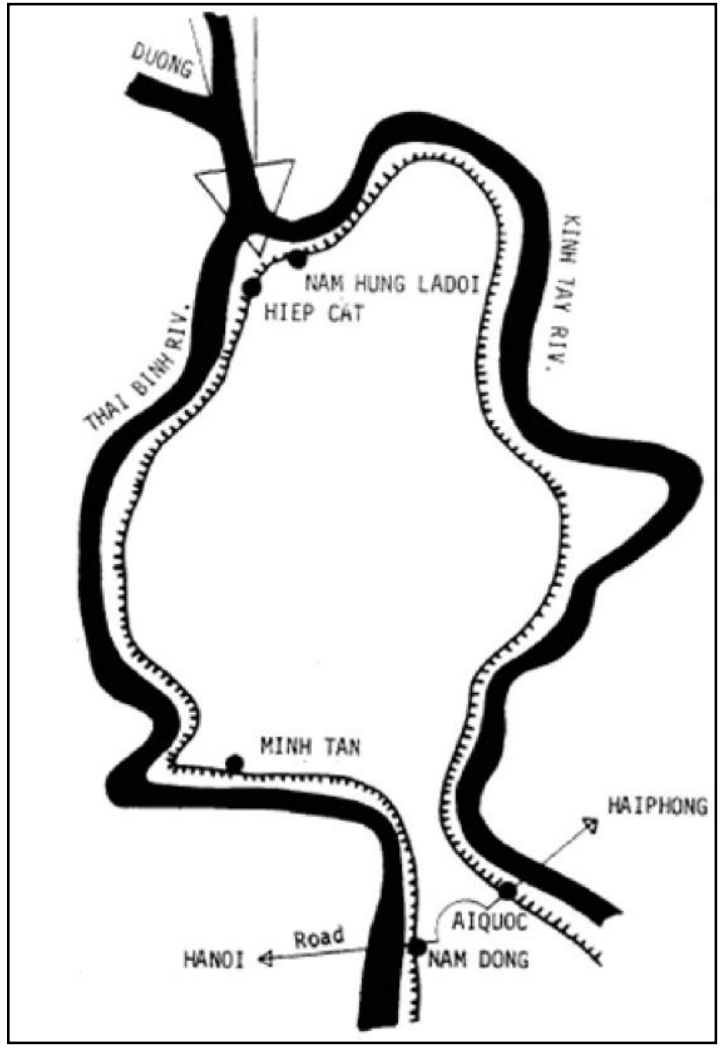

(a) The Nam Sach district is entirely surrounded by dikes and it looks in fact like an island hemmed-in by a peculiarly involved hydographic network. In the north spreads a net of rivers, the Thuong, Luc Nam, Cau and Duong Rivers which join together within a few miles and form the Tai Binh River. Shortly after it breaks up into two branches, Tai Binh and Kinh Thay, which enclose the district in its whole area, the dikes of the Nam Sach district were hit in six various points:

Figure 3: Nam Sach District 
- in the south, the dikes were hit on May 10 and 24, 1972, near the Aiquoc and Nam Dong villages; both localities are situated near the main Hanoi-Haiphong road, and it may be that the dikes were not the targets of these attacks (more than 150 bombs).

- the dikes were hit near Nocti and Ninh Tanh on July 9, 1972. At Nocti, the hit is in the concave part of a bend, that is to say, at the point where the pressure of the current is the strongest at high-water time. At Minh Tanh, 24 bombs destroyed the dike over a 300-foot [92 m] long section (more than 75,000 cubic feet $\left[2,124 \mathrm{~m}^{3}\right]$ of earth had to be moved to carry out the repair). The choice of that point is certainly explained by the fact that it is peculiarly difficult to repair the dikes at this point, for the surroundings are very low and marshy and it is hard to find anything other than water-soaked soil, quite an improper material for making a good repair.

- the dikes of Nam Sach district were especially hit in their northern part near the villages of Hiep Cat and Nam Hung, on July 9 and 21, 1972. The reason why the U.S. Air Force chose these points is quite obvious since they are situated exactly where the waters have just met and flow almost perpendicularly to the dikes, thus exerting a peculiarly high pressure. Should the dikes break at that point, the stream need only go straight on to flood the whole district and to inundate the some 100,000 people who live there.

It is important to point out that the dikes situated near the village of Nam Huong were, because of its importance in the hydraulic system, attacked in July 1967. This is not the only example of attacks being performed against points previously bombed between 1965 and 1968 .

(b) The northern part of the Thai Binh Province: This region is bounded on the south by the Red River and on the north by one of its branches, which forms the Traly River. These two waterways, both of which flow above an alluvial cushion, border a sort of long gutter which gives on to the sea in the east, became possible to make this "plot", or gutter, inhabitable - today over 600,000 persons live there - when dikes were built along the Red River and the Traly River, as well as along the coast. However, at low tide, the rain that falls in this vast gutter has to be drained and this is the role played by the important Lan locks.

The bombings have targeted the most essential points of this complex hydraulic organization[. T] o begin with, the Lan locks (figure 4). This installation is located far from any other target. Between May 24, 1972, and July 29, it was attacked nine times and, in spite of the existing destruction, three new raids were carried out during the first week of August no doubt to make repairs impossible. Prevented from flowing towards the sea, the waters began to accumulate in the rice fields where a considerable part of the harvest may be considered lost. 


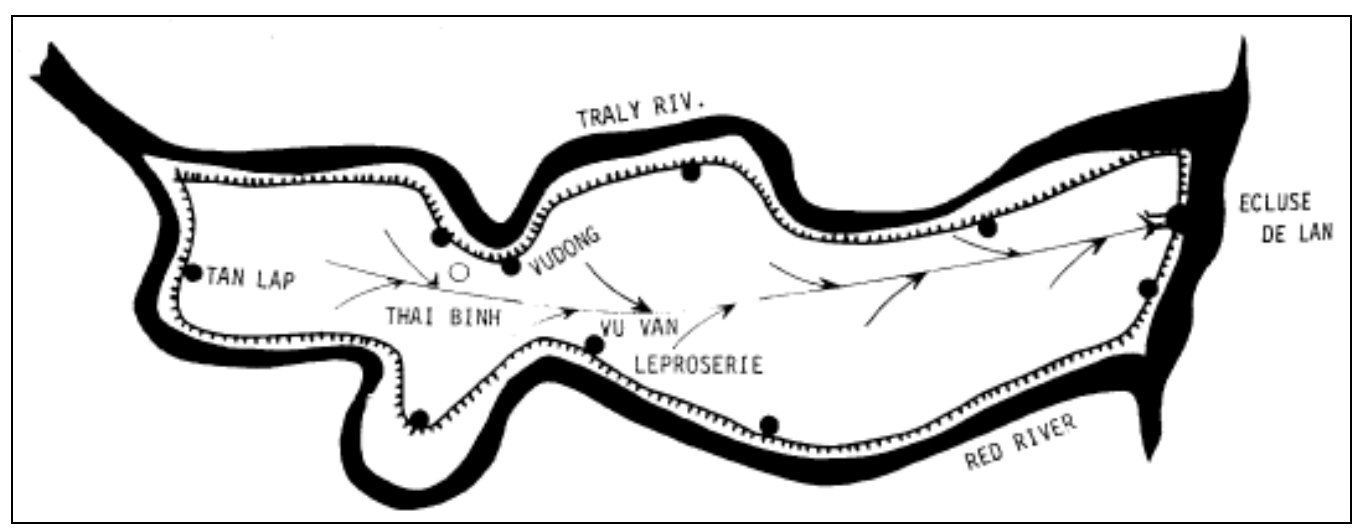

Figure 4: Southern part of the province of Thai Binh

We visited the Lan lock on August 3 (we went up a very small track) and we were able to verify that it was located very far from any other target, far from inhabited areas, between large coastal swamps and big rice fields. This lock which plays a decisive role had already been attacked in 1968. We were also able on August 3, to visit the part of the dike on the Traly River, attacked on July 21 near the village of $\mathrm{Vu}$ Dong (Kien Xong district): 11 bombs made craters close to the dike (less than 150 feet [46 m] away) thus creating severe cracks over a 600 feet [183 m] long section. One bomb dug a crater directly into the dike. During this bombing, which hit peasant dwellings located near the dike, 9 persons were killed, 9 severely injured. At the time we were there, most of the damages had been repaired, but the sections of the dikes which had to be reconstructed could be easily detected.

On August 4, 1972, we were able to verify the damages caused on the Red River dikes near the village of $\mathrm{Vu}$ Van (Vu Thu district). During the attack on July 31, 20 bombs were dropped on two points situated about 1,500 feet [457 m] from each other: the first was near a school which had been partially destroyed, and whose director was killed; the second was near a big leper-hospital, the second most important in the Democratic Republic of North Vietnam: 1,100 lepers were warded there when the bombings took place: 5 of them were killed, 10 others injured. The buildings of this hospital - which was created quite a long time ago (4 big buildings bordered by 3 big churches) - are extremely easy to locate and it is logical to think that the dike was attacked at this very point in order to make the mending work as difficult as possible. For, rightly or wrongly, the Vietnamese do peculiarly fear contagion (I noticed it myself that the Vietnamese who were with me were worried about the fact that I had wandered among the buildings of this leper hospital in order to complete my notes). Is it a consequence of this collective fear that they had not yet started to repair this dike section even though it suffered serious damages (a succession of large cracks in a radius of 150 feet [ $46 \mathrm{~m}$ ] around the craters)? 
The attack on July 11 against these two sections of dikes was directly eyewitnessed by a group of about twenty European journalists who had come to verify the damages made by the attack that took place on July 9. I have taken the deposition of Mr. Jean Thoraval, an A.F.P. [Agence France-Presse] correspondent. The journalists (who had come to observe the damages to which the dikes were subjected saw about ten Phantom F4 planes approaching: at first they kept flying very high, then they went down to $1,500-1,800$ feet [457-549 $\mathrm{m}$ ] and started bombing the dike. The journalists could verify that there was no other possible target (no road, no structures), as well as no anti-aircraft defense.

I visited the Nam Hung and Hiep Cat dikes on August 9. I noticed a large number of craters made on both sides of the dikes (which had been repaired). During the time I was there, along with Doctor Aarts from Amsterdam and his wife, I witnessed the explosion of a time-bomb (August 9, 1972, at 10:15 a.m.). It dropped near the village of La Doi, half-way between Hiep Cat and Nam Hung. This bomb was one of the six delayed-action devices dropped on July 11: three of them exploded during July, one on August 9; two others had not exploded at that time.

In addition there have been four bombings on the northern dikes of the Traly River and three on those of the Red River in the South. It should be pointed out that the bombs are especially aimed at the concave parts of the dikes' bends where, at highwater, the strongest pressure from the current is concentrated. It should also be pointed out that in two places time-bombs were used and that of 14 bombs dropped July 14 on the Red River dike near the village of Tan Lap, 13 exploded at different intervals (some of them 6 hours later, and others up to 21 days later).

Thus the "operation" on the southern part of the Thai Binh Province can be summarized as follows: On the one hand, it was intended to make breaks in the dikes at the most strategic points which, repaired or not, would risk breaking open again at high water (actually it is very difficult to properly pack the soil, which already contains too much water as a result of the summer rains, so that places that have been repaired remain very vulnerable): and, on the other hand, it was intended to block the locks to disturb water evacuation towards the sea. At the very least, part of the rice-fields is flooded and the food sources of 600,000 people are jeopardized. The maximum effect would be felt if there were severe flooding in that a great number of villages situated below the level of the alluvial cushions would be in danger of being flooded in case of a sudden break in the dikes (either at points where they have been repaired in a way that could not be perfect at this time of year, or at points where further bombings have taken place). These bombings continued to hit not only the river dikes but also the coastal dikes, which were constantly pounded by Seventh Fleet artillery. The locks constituted especially frequent targets since their destruction could bring about either the accumulation of a considerable volume of water in the inhabited and cultivated areas, or sea-water flooding, which makes the soil unfit for cultivation for several years. 
Finally, a more complete understanding of the systematic, action carried out against the hydraulic system of North Vietnam may be had if, in addition to what has been described, it is pointed out that the Nha May Gho Khi factory (near Hanoi) which furnished the material required for repairing the locks and other hydraulic installations was razed to the ground on August 5 by particularly intensive, precise bombing.

The fact that bombing of the dikes was localized in the Red River delta proves the deliberate and carefully premeditated nature of the operation. If it were not in the logic of the bombing to hit the dikes at points most vulnerable during high water, points at which their protective role is essential, and in the regions in which the greatest number of villages liable to be submerged are located, these bombings would have been differently located; the dikes situated near the big traffic centers and in the neighborhood of the big cities would have been hit much more frequently.

\section{Meta-Analysis of Bombing Targets}

The American administration, after admitting that the dikes might have been hit, declared that the resultant destruction was minimal. It is therefore important to examine closely the effects of the bombings on these installations. The most frequently used bombs in this kind of attack weighed between 500 and 1,000 pounds [227-454 $\mathrm{kg}]$. When such bombs hit the dike directly, they make craters from 20 to 22 feet [6.1 to $6.7 \mathrm{~m}$ ] deep and about 35 feet $[11 \mathrm{~m}]$ in diameter (figure 5). But the consequences of bombing are not limited to these craters, which are the most spectacular but not the most serious aspect. The shock caused by explosion of the bomb causes a series of fractures and cracks, over a radius of 50 yards [46 m], which seriously jeopardizes the resistance of the dike. Frequently bombs falling on both sides of the dike, about a hundred feet $[30 \mathrm{~m}]$ from it, have more dangerous results than holes made in the dike through direct attacks. For the cracks are not all immediately visible; the risk is that they will appear suddenly as a result of pressure from flooding. As a general rule, in order to prevent sudden bursting of a dike as a result of water pressure, or its collapse following what is termed the "fox" phenomenon (water gradually digs a sort of tunnel under the dike, at the point of the crack), one must remove all the earth from places where cracks might have been caused by the explosion of a bomb. It is not enough, therefore, to fill in the craters. A segment of the dike that is three-or four-times larger than the excavation caused by the explosion must also be rebuilt.

During the rainy season, repairing a section of ripped open or cracked dike is difficult work and necessarily imperfect. Actually, the clay-and-sand-mixed silt used for constructing and repairing dikes at that time contains too much water for it to be properly compacted. The repaired sections remain fragile, therefore, and the risk exists that they will give way under the pressure of particularly severe flooding. The closer the bombings took place to the period of approaching high-water, the more dangerous were their effects: on the one hand, the river may immediately rush through the 
opening and rapidly widen it; on the other, it becomes more and more difficult to repair the dike with water-soaked earth.

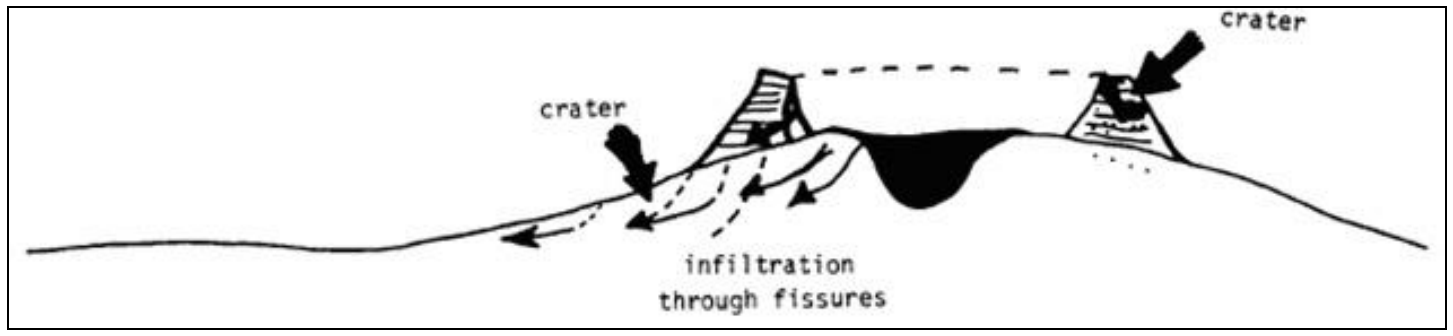

Figure 5

Unlike the bombings carried out against the dikes in 1965, 1966 and 1967 which were interrupted before the heavy rains and high-water, the attacks that began in April 1972 continued not only into July but also through August. Because of this fact, the risk of severe breaks in the dike network remained considerable, in spite of the immense effort made to repair the damage. For not only could the rebuilt sections give way because of fragility, but continuation of the bombing seemed destined to cause irreparable breaks, if one takes into account the high-water. The threat of flooding existed for the greater part of the areas under cultivation (rice is a plant that dies if it is under water longer than four days) and it may be estimated that $1,500,000$ to $2,000,000$ people could have been drowned in case of a particularly violent water-rise in the lower regions. This estimate corresponds to the prognosis made several years ago by certain American military experts, to the effect that "bombing the North Vietnamese dikes would produce an effect comparable to that of a hydrogen bomb: the entire delta would be flooded, the summer and fall rice crops would be destroyed, and two to three million of the population would die of drowning or of hunger". 